\title{
An Integrated Labor-Management System for Taco Bell
}

\begin{tabular}{ll}
\hline Jackie H uet er & Taco Bell Corporation \\
& 17901 Von Karman \\
& Irvine, California 92714-6212 \\
& \\
Will iam Swart & College of Engineering and Technology \\
& Old Dominion University \\
& Norfolk, Virginia 23529-0236
\end{tabular}

Taco Bell Corporation has approximately 6,490 companyowned, licensed, and franchised locations in 50 states and a growing international market. Worldwide yearly sales are approximately $\$ 4.6$ billion. In 1988, Taco Bell introduced six coremenu items for the reduced price of 59 cents and offered free drink refills. Taco Bell has since continued to change and innovate. Its new strategy meant restructuring the business to become more efficient and cost-effective. To do this, the company relied on an integrated set of operations research models, including forecasting to predict customer arrivals, simulation to determine the optimum labor required to provide desired customer service, and optimization to schedule and allocate crew members to minimize payroll. Through 1997, these models have saved over $\$ 53$ million in labor costs.

$\mathrm{T}$

aco Bell was established in 1962 by

Glenn Bell in Downey, California. By the early 1970s, Taco Bell Corporation was a booming regional chain and had gained the food service industry's attention.

PepsiCo, Inc. purchased Taco Bell in 1978 and transformed it into a dynamic, inter- national fast-food business. By the mid1980s, it had achieved a successful steadystate position in the fast-food marketplace by delivering consistent food quality, service, and value to its customers. As is typical in the industry, operating procedures and management principles evolved as a

Copyright (c) 1998, Institute for Operations Research

and the Management Sciences

INDUSTRIES-AGRICULTURE/FOOD

SIMULATION-APPLICATIONS

PROGRAMMING-INTEGER, APPLICATIONS

FORECASTING-APPLICATIONS

INTERFACES 28: 1 January-February 1998 (pp. 75-91) 


\section{HUETER, SWART}

consequence of a long process of trial and error, based occasionally on adapting what other quick-service companies were doing to the Taco Bell environment.

Taco Bell labor costs represent approximately 30 percent of every sales dollar and are among the largest controllable costs. They are also among the most difficult to manage because of the direct link that exists between sales capacity and labor. Because the product must be fresh when sold, it is not possible to produce large amounts during periods of low demand to be warehoused and sold during periods of high demand, as is typical in most manufacturing enterprises. Instead, the product must be prepared virtually when it is ordered. And since demand is highly variable and is concentrated during the meal periods (52 percent of daily sales occur during the three-hour lunch period from 11:00 a $\mathrm{m}$ to 2:00 pm), determining how many employees should be scheduled to perform what functions in the store at any given time is a complex and vexing problem.

Because of the complexity of the labormanagement problem described above, the traditional approach to managing labor costs is to establish a policy decision that indicates what percentage of sales the company is willing to allocate to labor cost in order to meet prescribed financial objectives. It is then up to those who manage store operations to develop rules and procedures that seek to maximize the level of service and quality that can be delivered with the given amount of labor assigned to the store. Over time, these rules and procedures evolved into a body of "tribal knowledge" that was applied manually at every restaurant. In 1988, Taco Bell invested in an in-store computer network, which allowed it to develop more advanced-information solutions. The result was the field-automated-staffing program, FAST. FAST, like the traditional approach, was a top-down control system that allocated a percentage of sales to labor costs to meet prescribed financial targets. It still told managers what to achieve, but not how to do it, and managers still had to rely on experience to do it well. If the amount of labor allocated to stores appears insufficient to meet customer service

\section{Labor costs represent approximately 30 percent of every sales dollar.}

goals and maintain sales, intense debates occur between financial executives and operations executives. Financial executives typically resist increasing the labor-cost allocation, and operations executives typically argue that sales are being lost because they cannot assign enough labor to the restaurants to get everything done.

In 1988, Taco Bell management decided to move the company to a new plateau in terms of market share, per-unit sales, and operating profits. To do this it developed and implemented aggressive new strategies and tactics. One of the earliest and most visible of the new strategies was "value meals." Subsequent strategies affected virtually all aspects of Taco Bell, including new store design and layout, products, equipment, and customer service with and without self-service beverages. However, before management could make any decisions to implement change, 


\section{TACO BELL}

it had to know what impact this change would have on labor cost and customer service. The fast-service food industry had long ago learned the lesson that America Online recently endured: Increasing demand without anticipating its effects on operations can make for a very unpleasant experience for all.

During the planning phase that preceded the adoption of the new "value strategy" (value meals and associated changes to the system's stores), Taco Bell's managers realized they needed answers to questions they had never before asked. They needed to know what impact operational decisions would have on labor costs and speed of service. The existing labor system, FAST, was not designed to answer such questions. It was designed to respond to questions whose answers could be inferred from the past. It could not be adapted to yield the information needed to support the many decisions that had to be made in the new environment. Also, as the company institutionalized new policies, FAST would become inadequate because the experience base upon which operations management had been successful in the past would no longer reflect the company. As a result, Taco Bell began to look for new ways to answer the many questions that accompanied each of the operational decisions that managers had to make to ensure that the value strategy would be successful.

Once it understood and accepted the need for better and more timely information, management made a commitment to introduce IBM-compatible personal computers in every Taco Bell store linked to a centralized mainframe system at the cor- porate headquarters. This system, together with a number of software modules to automate management paperwork, collect and transmit transactional data to the mainframes for financial control, and control aspects of store operations, was dubbed TACO (total automation of company operations). By replacing FAST with a new, comprehensive, integrated labormanagement system as an integral part of TACO, the company could take advantage of and accelerate the deployment of the new hardware and software to the field. Furthermore, with the new labor management system as a standard component of a comprehensive restaurant-management system, Taco Bell and its franchisees and licensees could manage labor in a consistent manner across the entire system. The results would be reflected in greater consistency of service and, hence, greater customer satisfaction and brand equity. It could also serve as one more tool to make investing in a Taco Bell store more attractive to prospective franchisees.

\section{Project Genesis}

In Taco Bell's search for new ways to answer the many questions that accompanied proposed operational decisions, one individual emerged as a champion for the use of operations research as a means to support decision making in the new environment. This individual, Howard Frantz, manager of Taco Bell's newly established industrial engineering function, convinced management to fund the development of a new labor-management system (LMS). The study was to be conducted under his leadership assisted by a newly formed labor steering committee. This steering committee consisted of Taco Bell's six zone vice 


\section{HUETER, SWART}

presidents and represented all the company's operations management. This committee would (1) provide input and guidance regarding labor issues, (2) provide access to internal resources, and (3) review and evaluate results. The first directive of the committee was that Howard Frantz seek the advice and counsel of the leading authority on the use of operations research in the food service industry. This led to the hiring of Dr. William Swart as a strategic consultant for the development of the new LMS. Dr. Swart had pioneered the use of operations research in the industry and received an Edelman finalist award in 1981 for his accomplishments. To complete the LMS development team, Howard Frantz hired one full-time industrial engineer, enlisted a job shopper, contracted for industrial engineering consulting services, and enlisted the services of data-entry and programming personnel. Howard Frantz and William Swart held the project's kick-off meeting with the steering committee on January 11, 1991.

In its deliberations with the LMS development team, the steering committee identified the following key objectives of Taco Bell's new labor-management system: -Be responsive and economical;

- Be able to predict labor requirements that minimize labor cost and meet all corporate standards for hospitality, quality, service, and cleanliness for any existing or planned restaurant configuration;

- Serve as an effective and efficient instore labor-management tool to help the store manager to plan and schedule; - Serve as an effective and efficient tool for providing the labor required to achieve Taco Bell's financial targets;
—Provide timely feedback for controlling labor cost at all levels; and

- Have the inherent flexibility to evolve as Taco Bell evolves.

After appropriate deliberations among all stakeholders in the study and a search of the literature, we confirmed our earlier conclusion that these capabilities could be provided only by a model-based labormanagement system.

\section{The Restaurant as a System}

As a first step, we developed a conceptual system representation of a quickservice restaurant (Figure 1). The system is made up of three interacting segments: the customer, the delivery, and the production subsystems. We do not consider a fourth segment, the consumption subsystem (or dining area) because we focused primarily on the other three.

The restaurant system and more traditional manufacturing concerns are similar in many ways:

-Each product on the menu requires a well-defined sequence of assembly and processing steps, including packaging. -Multiple products compete for access to scarce resources (for example, fryers).

- The product line is a mix of standard products (for example, tacos) and customized products (for example, "hold the hot sauce").

-Raw material, in process, and finished product inventories must be maintained and managed.

-Distribution occurs through multiple channels (walk-in, drive-through, home delivery).

-An order consists of a variety of products that have to be assembled and packaged together. 


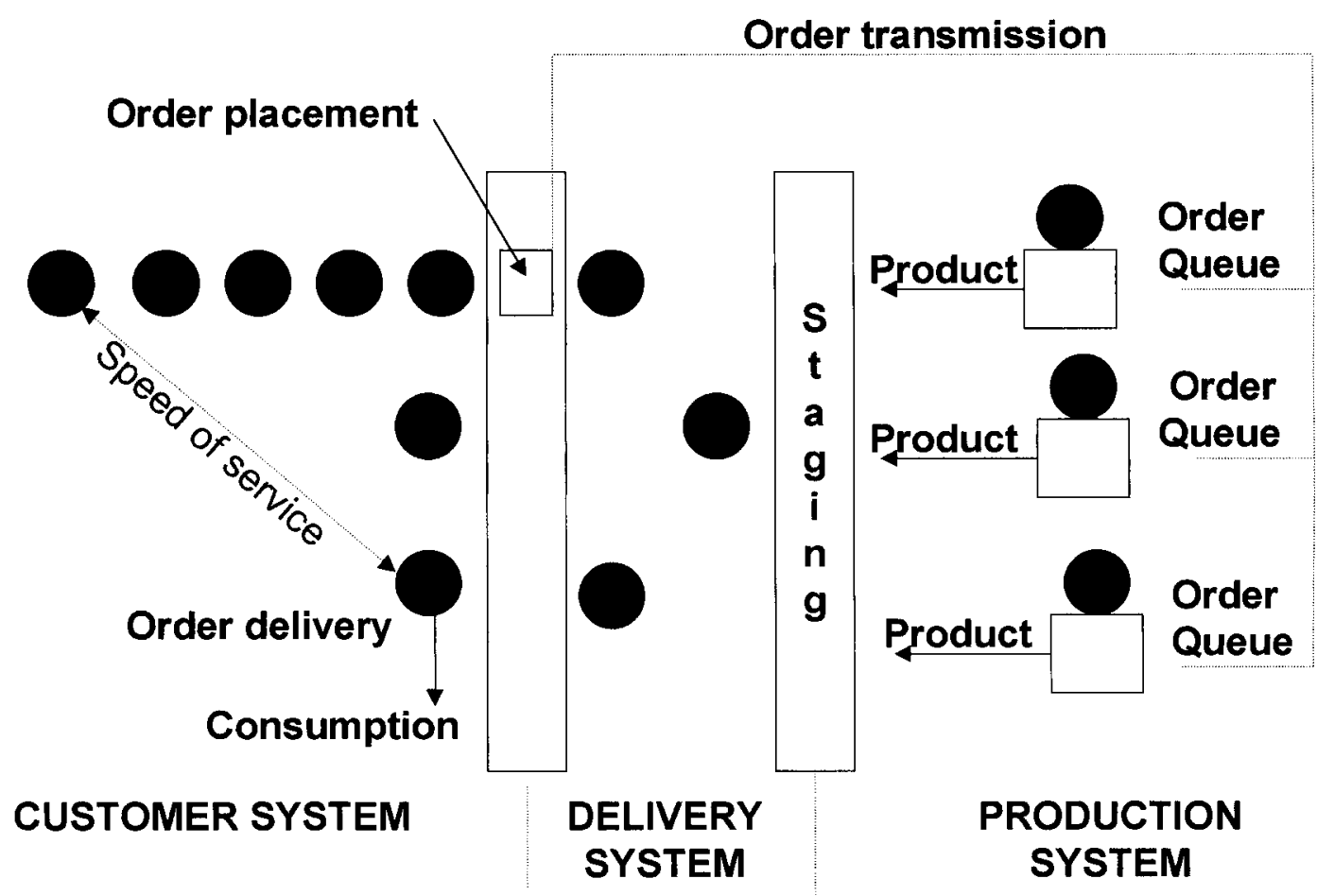

Figure 1: Representation of a quick-service establishment as a system, including its three subsystems, and the flow of information between the customer and the production subsystems.

-Employee productivity and training are highly correlated.

However, they also show some very significant differences:

- The acceptable lead time between placing an order and order delivery (speed of service) is only a few minutes (customers cannot wait a long time, in particular during lunch time in the work week, and they expect fast service).

-Finished product in inventory perishes in minutes (customers all like their food freshly prepared).

-Demand can easily fluctuate by 1,000 percent in a 30-minute interval (for example, between 11:30 a m and noon in business areas, stores can go from empty to crowded).

January-February 1998
-Ordering, production, and delivery take place under the same roof.

-Employee and management turnover is high.

\section{Model Conceptualization}

The total labor requirements in a restaurant can be categorized into three types: fixed labor, variable food-preparation labor, and variable customer-service labor. Fixed labor is that which is required and is largely independent of the restaurant's daily sales volume. Such labor includes, for example, that which is required for cleaning between the closing of the restaurant at night and its opening the next morning. Variable food-preparation labor is that which is required to meet the restaurant's daily operating needs but is not 


\section{HUETER, SWART}

instantaneously linked to customer volume, such as, for example, preparing and restocking ingredients on the production line. Both of these categories of labor can be scheduled at the discretion of the restaurant manager (within limits). However, the third category of labor, variable customer labor, is that which is required to satisfy a particular customer's order, such as order taking, making change, producing a custom product, and order delivery. There is little or no discretion as to when this work must be performed, and the availability of this category of employees must match the highly variable flow of customers to the restaurant. It also accounts for up to 80 percent of the restaurant's labor requirements during the day. Because of the discretionary nature of when the fixed labor and variable foodpreparation labor can be performed, people have used traditional time-study techniques successfully to determine restaurant requirements for these categories. However, determining variable customerservice labor requirements is much more complex.

\section{Defining the Relationship Between Labor} and Service Quality

Different customers order different items and combinations of items. From 20 to 80 percent of these orders, depending on region, require custom preparation (no hot sauce, extra hot sauce, and so forth). Consequently, few products are inventoried and those that are can be held for only a few minutes. As a result, customer arrivals drive the work to be performed in the restaurant. The work to be performed in a quick service restaurant is commonly defined as providing quality food with good service in a clean environment, or QSC. Each of these three attributes is defined according to corporate standards and can be measured by objective methods, subjective methods, or a combination of both.

Although Taco Bell sees the three attributes as equally important, good service, as measured by speed of service, is most directly related to revenues. The three-hour lunch period in Taco Bell stores accounts for approximately 52 percent of daily sales. Within that period, the busiest hour can account for 15 to 25 percent of daily sales. Most quick-service restaurants have waiting lines during this period. Consequently, speed of service determines throughput and hence sales. If service time decreases, sales capacity increases and vice versa.

Taco Bell has and will continue to invest heavily in strategies to improve productivity and speed of service, including radical new kitchen designs, more visible menu boards that promote quicker ordering, and all manners of automation, including robotics. However, speed of service depends on labor. Given that labor is deployed correctly, additional labor means increased sales capacity, faster service, and improved quality and cleanliness. But it also means higher labor costs.

The crux of the labor-management problem then lies in understanding the quantitative trade-off relationship between labor and speed of service, and speed of service and revenues. To our knowledge, the specific relationship between speed of service and revenues has not been determined at Taco Bell or at any other organization. However, from a pragmatic point of view, 
we [Swart and Donno 1981] have followed and defined the relationship in terms of the number of customers that are likely to balk (leave the line and the store) as a function of speed of service. A study we performed assessed when customers would be likely to leave a waiting line because they perceived waiting time as excessive. The results indicated that customers in line perceive that waiting time is "a couple of minutes" although actual waiting time can reach five minutes. After actual waiting time exceeds five minutes, customer perception of waiting time increases exponentially (Figure 2). The higher the perceived waiting time is, the more likely a customer is to "balk." Further studies quantified the variability of the waiting-time distribution. Using this probabilistic information, we determined that a three-minute average time in the queue (from arrival at the restaurant until food is delivered) ensures that only 2.5 percent of customers that wait are likely to balk. We discussed this finding with senior managers and they decided that, at this stage of the process, achieving a service level of consistently delivering food to customers within an average of three min-

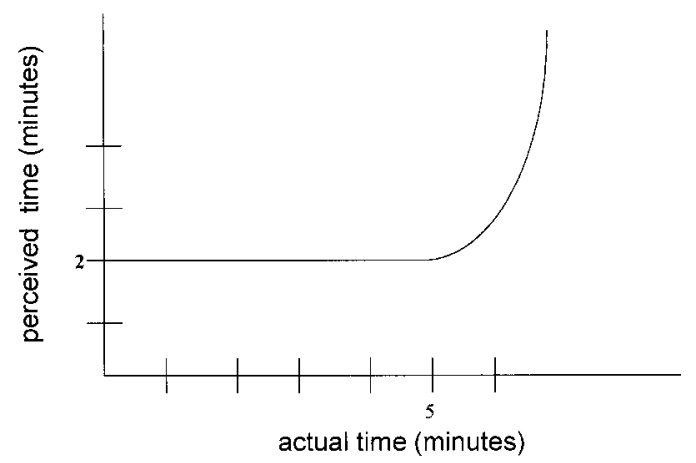

Figure 2: The relationship of perceived versus actual time spent in line by quick-service establishment customers.

January-February 1998 utes would be a significant improvement.

Furthermore, they saw the resulting low

risk of balking as acceptable. We agreed to review the risks and consequences again later.

\section{Addressing Store Management Requirements}

To satisfy one of the key objectives, the new labor-management system had to serve as an efficient and effective in-store labor-management tool. It had to help the manager plan shifts. That is, it had to determine who should begin work when and for how long each day in such a manner that payroll is minimized. An integral part of that decision is planning when employees should start and finish their allocated shifts. To avoid the confusion of having employees begin or end their shifts at any time, it is common to start and end shifts at discrete points in time, such as on the hour, on the half hour, or on the quarter hour. The selection of start and end points is critical. For example, if they can start only on the hour, then during lunch employees could either start at 11:00 a m and have little to do until noon or they could start at noon amidst the confusion of the busiest time of the day. Consequently, it is desirable for employees to begin and end their shifts in the smallest practical time increments (usually at 15-minute intervals, but no longer than 30 minutes) so that labor scheduled in the store can most closely adhere to predicted demand. Scheduled labor and labor demanded are not usually the same because employees, once brought to the store to work, must be guaranteed a minimum shift, the length of which depends on state law and local labor conditions. 


\section{HUETER, SWART}

To minimize payroll and deliver desired customer service, store managers require a tool that will help them to determine which employee should begin work and which employee should go home at every time interval of the day for every day of the week. At the beginning of this study, this interval was 30 minutes because of restrictions imposed by the in-store datastorage devices. Today, the company is overcoming this limitation and implementing a 15-minute time increment systemwide. In addition to the number of employees required, such a tool must indicate where they must be positioned and how they are to share the required duties. And before it can determine that, it must know how many customer transactions will take place at the store during every 15-minute interval of every day of the week.

This means that the new labor management system needed three major components: (1) a forecasting model for predicting customer transactions; (2) a simulation model to translate customer transactions to labor requirements; and (3) an integer programming model to schedule employees to satisfy labor requirements and minimize payroll. These models must operate in concert while permitting the manager to intervene and make appropriate revisions before implementing the results (Figure 3).

\section{The Forecasting Model}

Customer transactions during a 15-minute interval are subject to many sources of variability, including but not limited to time of the day, day of the week, week of the month, and month of the year. To eliminate as many sources of variability as possible, we separated all customertransaction data for all stores into a num- ber of independent time series, each representing the customer-transaction history corresponding to a specific 15-minute interval during a specific day of the week. For example, the customer-transaction history at a particular store for all Fridays from 9:00 to 9:15 a m constituted the time series to be used to forecast customer transactions at that store for future Fridays from 9:00 to 9:15 a m.

To produce the data on which to base a weekly staffing schedule, the forecasting procedure must forecast next week's customer transactions for each 15-minute interval of every day of the week that the restaurant is open. It does this by forecasting the transaction time series associated with each 15-minute interval of the restaurant's daily open time during the week one period ahead. In an unpublished study conducted by one of us (Swart), the complete array of forecasting methods included in Makridakis and Wheelwright's [1978] Sybill/Runner forecasting system was used to predict one-period-ahead sales (sales and transactions are directly correlated) for 30-minute interval data for all company-owned Burger King restaurants. The forecasting procedure that minimized the average square deviation between actual and predicted data was the naïve method (the projection is the same as the last data point). With the understanding provided by that experience, we set forth to determine the best forecasting procedure to use for Taco Bell.

Although some argue that there is some evidence that trend and seasonal patterns might exist in Taco Bell data, we could not extract a reliable database of multi-year, 15-minute-interval customer transactions 
TACO BELL

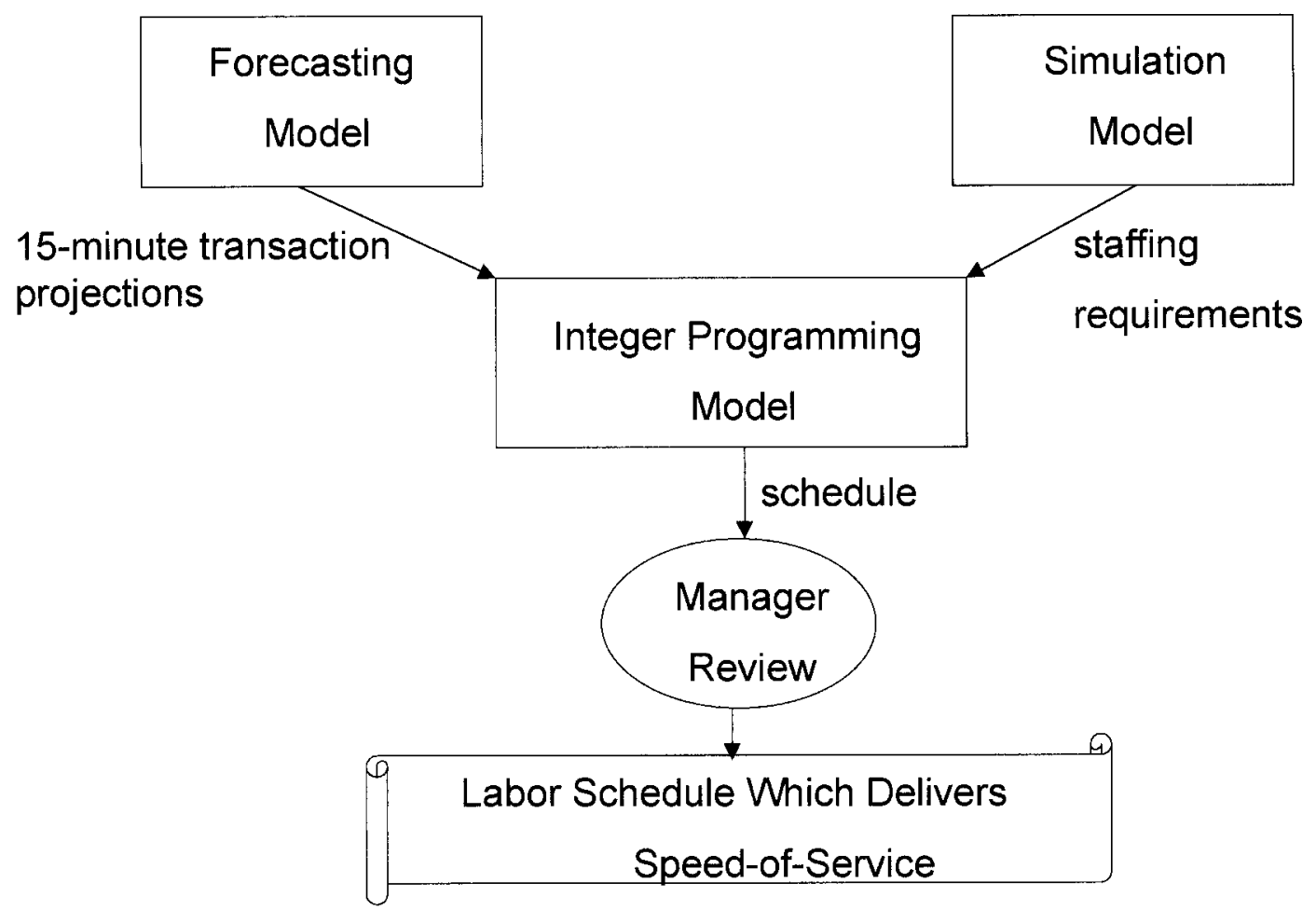

Figure 3: The structure of Taco Bell's labor-management system.

by day from the corporate databases because the corporation had not collected such data in the past. In cooperation with Taco Bell's information technology group, we identified 200 restaurants that had recently upgraded their telephone lines to take part in an effort to collect 15-minuteinterval transaction data. We developed and implemented a rolling database containing six weeks of in-store and drivethrough transaction data, the maximum that restaurant in-store computers could store. We then conducted tests to determine which applicable forecasting methods would yield the least mean square deviation. The methods tested were (1) moving averages (from one through six periods); (2) moving averages adjusted for linear trend; and (3) moving averages ad- justed for quadratic trend. Because the time series consisted of only six data points, we did not consider using exponential smoothing. The results indicated that a six-week moving average was best.

Taco Bell incorporated this forecasting methodology in each store's computer system. The computations are transparent to the restaurant manager and do not tax instore computer resources. The model compares weekly activity projections obtained from the forecasting model to statistical forecasting control limits that are continuously updated. The model also reoptimizes the length of the moving-averageperiod when it declares the forecasts out of control, but this is also transparent to the restaurant manager. The system provides the manager with forecasts obtained 


\section{HUETER, SWART}

from scientific approaches. The manager, however, has the authority to modify the forecast based upon known events. If these events are foreseeable, the manager can assign a name to them and include them in a special event database and use it to adjust future forecasts (Figure 4).

\section{The Simulation Model}

A forecast of transaction levels provides information essential to the laborscheduling process, provided that the relationship between transactions and required labor is known. Simulation has proven effective in solving this particularly complex problem in the fast-food environment [Swart and Donno 1981].

Taco Bell restaurants have continuously evolved since 1962. Consequently, there is no such thing as a standard Taco Bell restaurant, and no single simulation model can provide answers that apply across the system. Thus we needed a simulation model that could be easily adapted to rep- resent a variety of restaurant configurations. Management also expected that once the models were in use, it would use them to seek answers to a great number of questions in a short time. Object-oriented simulation approaches are rapidly reconfigurable. Taco Bell selected MODSIM, an object-oriented simulation language, as its simulation modeling tool [Godward and Swart 1994].

To develop and use a simulation model, one must develop and collect quite a bit of data. Almost everything that takes place in a restaurant, from customer arrival patterns to the time it takes to wrap a taco, has to be translated into reliable and accurate data if the simulation model is to predict actual behavior. For example, we collected interarrival times for in-store and drive-through customers at a representative sample of restaurants. Based on applying the Kolmogorov-Smirnov test for goodness of fit [Solomon 1982], we found

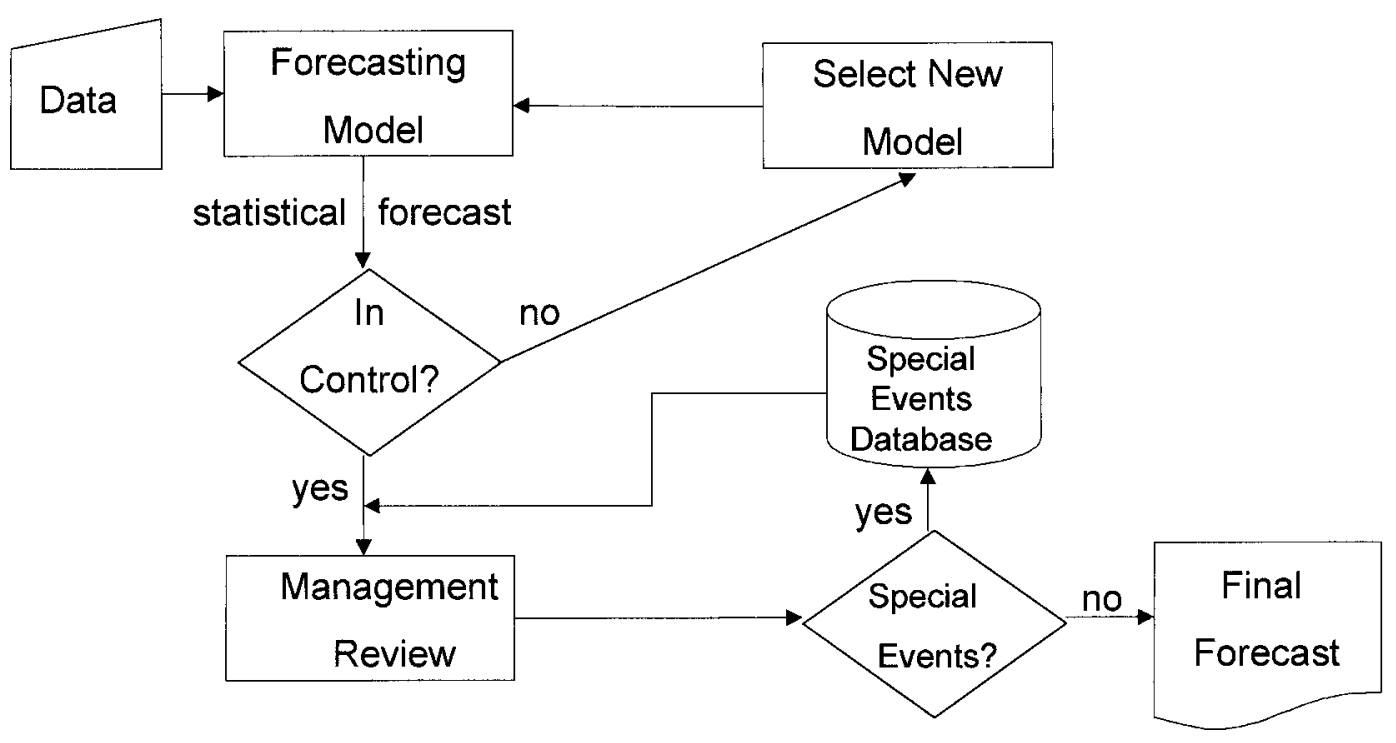

Figure 4: Flow chart depicting the process used to transform a statistical forecast into a final forecast at Taco Bell. 


\section{TACO BELL}

that there was no reason to reject the hypothesis that they followed an exponential distribution, regardless of the sales volume of the particular store(s) from which we obtained the data.

In some cases, determining the nature of the data to use to populate the model became the subject of debate. For example, should one measure the time required to prepare a breakfast taco (or any other product or process) by observation and include observed statistical variability, or should one obtain the time via a predetermined time standard method, such as MOST [Mishra 1982], which yields deterministic results? Taco Bell elected to collect data for the variable customer-service labor by taking slow-motion videotapes of trained employees working at a normal pace using acceptable procedures in actual restaurants. We then analyzed these videos and expressed the resulting standards as an empirical frequency distribution to reflect the stochastic nature of the real world.

Collecting all the data required to populate the simulation model became the major task we had in developing the LMS in terms of time and effort. For example, we had to conduct time studies and data analyses for every task that is part of preparing every product on the menu board. We had to time every step of the process of interacting with the customer, including the time to place an order, the time to make change, and the time a customer took to walk from the cash register to the foodpickup area. We had to repeat this effort to account for each type of restaurant in the system, because the travel distance, and hence time, of the customer from the cash register to the pickup area, and of the employee from the preparation area to the finished product area, varies. Thus the hours devoted to collecting the data greatly exceeded those devoted to modeling.

Once we had verified and validated the model, we obtained the minimum labor requirements to meet any level of activity by staffing the model with the minimum acceptable store complement (a policy decision at Taco Bell that takes into account

\section{This system was dubbed TACO (total automation of company operations).}

safety as well as operational factors). We then increased simulated store-activity levels by increments until it became impossible to keep average customer-waiting time below three minutes. At that time, we increased the staffing level by one, explored the logical assignment of duties, and adopted that assignment of duties that allowed for the maximum increase in store activity while maintaining service standards. Thus the model also determined the optimal deployment for each staffing level to maximize throughput and therefore service. We again increased the staffing level by one and incrementally increased the store-activity level, repeating the same process until additional staffing could not accommodate the increased activity level while maintaining speed-ofservice standards, or until it became physically impossible to add additional employees (Figure 5).

We captured the end result of the simulation process in a set of files containing 
HUETER, SWART

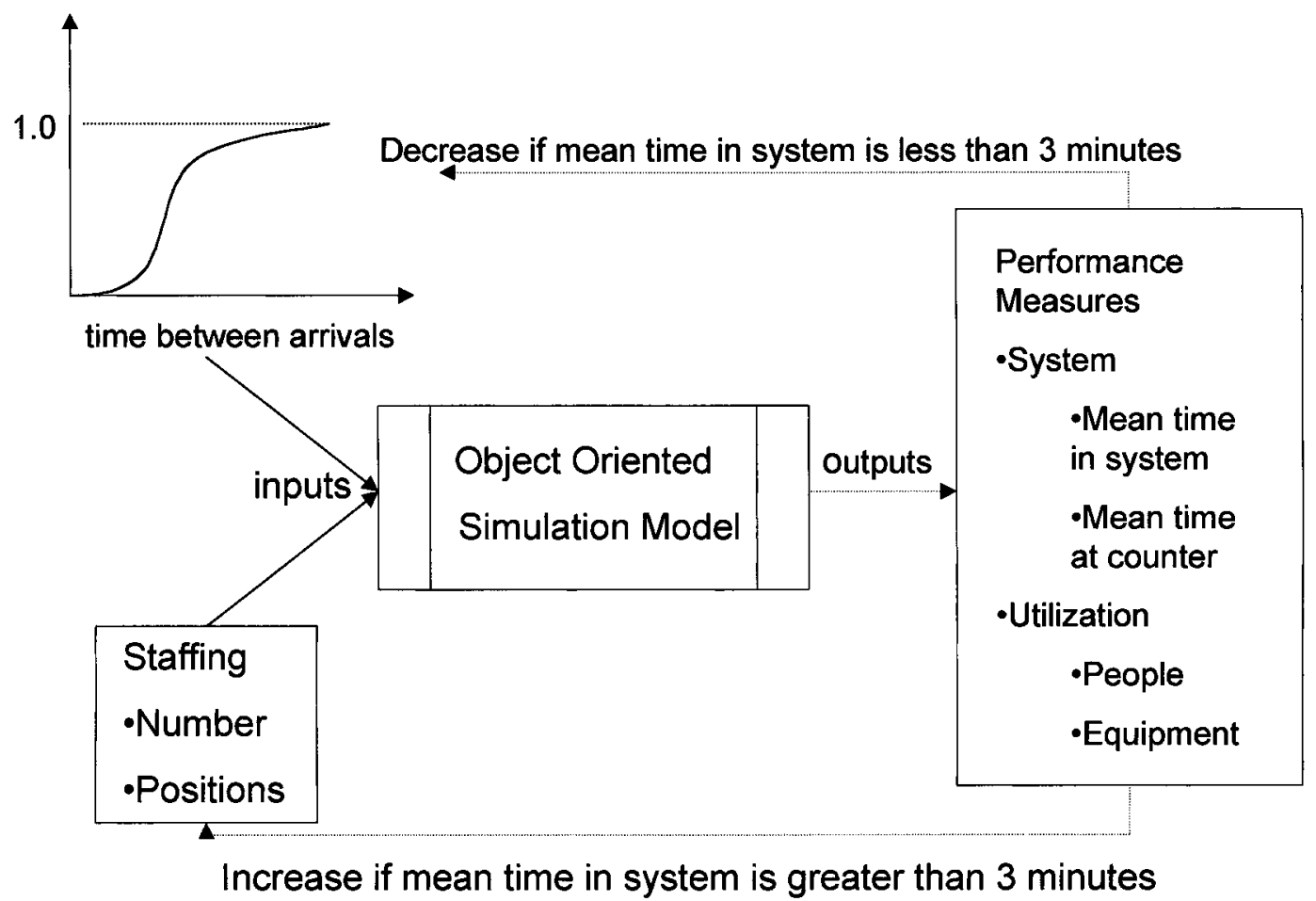

Figure 5: Flow chart depicting the iterative process used by Taco Bell to develop its staffing requirements.

the minimum staffing levels and duty assignments required to satisfy customerservice standards at each possible activity level. We tailored these files to each restaurant type and adjusted these to reflect the natural variability that exists in menu mix and check averages at each restaurant. We use simulation to make these adjustments when warranted. For many situations, however, we have developed adjustment factors by using various decision rules and heuristic processes. These files are used to generate data for the integer programming models.

\section{The Integer Programming Model}

In a Taco Bell restaurant, the total labor requirements consist of fixed labor, variable food-preparation labor, and variable customer-service labor. We use simulation models to determine the amount of variable customer-service labor that is required for any level of store activity. We use traditional time-study methods to calculate fixed labor requirements and express them as labor hours per day per total store-activity level (typically as a step function, for example, $x$ labor hours for sales to $\$ y, x+a$ hours for sales between $\$ y$ and $\$ y+b$, and so forth). The store manager decides when this labor will be performed-generally before the restaurant opens or after it closes.

We also use traditional time-study methods to calculate the variable foodpreparation time and also express it as a step function of store-activity level. How- 


\section{TACO BELL}

ever, unlike fixed labor, this labor must be performed at various periods during the day. Ingredients must be restocked on the production line periodically (more often during peak hours than during slack hours). Based upon projected store-activity level and such factors as the size of storage bins, the manager will know how many times they are likely to need restocking during the lunch period. Consequently, the manager can predict when this type of labor must be performed.

In the first phase of developing a model to schedule employees, we calculate the total labor requirements of a store for each 15-minute interval during the day as the sum of fixed labor, variable foodpreparation labor, and variable customerservice labor. The demand for total labor at any time interval must be satisfied by the number of employees in the store during that interval, regardless of when their shifts started. Thus, the solution to the employee-scheduling problem, as defined for Taco Bell, follows that described in detail by Godward and Swart [1994] and is an integer program with the decision variables representing the number of employees scheduled to begin their shifts at time $t$ and the length of shifts $s$. The value of $s$ is constrained by the minimum and maximum permissible shift lengths. The constraints ensure that the total number of employees working at time $t$ is equal to or greater than the number required. This formulation can be transformed into an equivalent network formulation and Ford and Fulkerson's [1962] out of-kilter algorithm is the basis for the solution algorithm. The objective function to be minimized represents the total payroll for the scheduling period and is obtained by putting the appropriate wage plus fringes in front of each integer variable.

Godward and Swart's model proved to be satisfactory, but it did not account for the fact that many stores have a limited number of employees on the payroll. Consequently, we augmented the model to include a constraint on the total number of employees that could be scheduled (for example, the sum of all variables had to be less than or equal to the number of employees on the payroll and available to work during that scheduling period). Unfortunately, this one constraint destroyed the characteristic that allowed us to represent the model as a flow network. Consequently, we would have to use more traditional integer-programming algorithms to schedule employees. But the overhead and time required by traditional solution algorithms made them infeasible to use within the Taco Bell environment. As an alternative approach, we decided to use generalized Lagrangean multipliers [Everett 1963] to eliminate this new constraint from the constraint set. The out-of-kilter algorithm provided the computational efficiency to solve the reformulated problem efficiently and within the store's computational resources.

The solution to the above-formulated employee-scheduling problem provides the manager with the set of shifts that will minimize payroll while satisfying all constraints. Although Taco Bell has the capability to automatically assign names to the shifts based on a number of criteria, store managers have preferred to do this manually because they can and often do assign desirable shifts as an internal reward or 


\section{HUETER, SWART}

incentive system for store employees. The manager enters employee names manually on the working screen created by the LMS after reviewing the model outputs and, if warranted, modifying them to reflect special and unanticipated store, market, or personnel circumstances. The outputs of the LMS also provide the managers with information useful in supporting their profit-and-loss responsibilities.

\section{Model Implementation}

We developed the individual modules and integrated them into a cohesive labormanagement system between 1990 and 1992, implementing them to all company stores during 1993. Prior to implementing it systemwide, we prototyped the integrated system and tested it in a sample of five restaurants. Once we achieved satisfactory performance in the five restaurants, we added an additional five restaurants to the test group. After a five-month test period, Taco Bell decided to implement the new LMS in all company restaurants. At the same time, we developed a measurement and validation process to quantify and document the benefits of the new system.

To measure and validate the LMS, we collected information on the use of labor from restaurants using the old FAST labormanagement system (part of the management routine in restaurants). At the end of each week, members of Taco Bell's operations-services group, assisted by members of the information-systemstechnology group and the restaurantsystems-engineering group, retrieved the previous week's sales data, and applied the new LMS process to those data just as a restaurant manager would. We then compared the labor use obtained by that process to that reported as actually used in the restaurants. We aggregated the results and reported the difference as actual labor savings. We used this process during the five-store and the 10-store operations test described above. After companywide implementation, we reversed the process. We reported the labor actually used under the new LMS system. We then applied the old FAST system to actual data. We then recorded the difference in labor used by the simulated application of the old FAST system and the new LMS system. Since 1993, the LMS system has shown a consistent difference of one less hour per day of labor than the FAST system.

\section{Implementation Cost}

From January 1991 until the LMS was fully implemented, Taco Bell budgeted $\$ 287,500$ to support the labor consultant, the job shopper, the industrial engineering consultants, and the programmers working on the project. Approximately $\$ 90,000$ was budgeted to support the simulation modeling effort, $\$ 80,000$ for the data collection and development effort, and $\$ 117,500$ for the combined tasks of developing the forecasting model and developing the integer-programming model. In addition, the industrial-engineering function grew into the restaurant-systemsengineering department. Today, this department has four individuals with training in operations research or industrial engineering who devote approximately half of their time to using the LMS to improve the efficiency and effectiveness of the Taco Bell system.

\section{Model Benefits}

Between 1993 and 1996, the number of 


\section{TACO BELL}

Taco Bell company and franchised restaurants using the new LMS system increased from 1,298 to 3,954. Labor costs saved through the use of the LMS system went from \$3.51 million in 1993 to $\$ 16.4$ million in 1996 (Table 1). Licensed stores are outside the scope of the LMS. Taco Bell licenses Taco Bell express stores, which deliver fast food beyond the traditional "four walls of a restaurant." They operate in such nontraditional locations as dispensing carts, kiosks, and mobile units and do not use Taco Bell's in-store processing systems.

The total savings in labor costs Taco Bell has achieved by using the LMS instead of the old FAST system over the four-year period, 1993-1996, are over $\$ 40.34$ million. These cost savings will continue to accrue each and every year in relation to the growth of company and franchised units in the Taco Bell system.

\section{Improving the Quality and Consistency} of Customer Service

The documented savings in labor costs are impressive. Other benefits may be even more significant. As a result of this study, Taco Bell now has a new, flexible, and adaptable methodology for determining how much labor it actually needs at each store and how to deploy that labor in

\begin{tabular}{lllll} 
& 1993 & 1994 & 1995 & 1996 \\
\hline $\begin{array}{c}\text { Company stores } \\
\quad \text { using LMS }\end{array}$ & 1298 & 2763 & 2785 & 2550 \\
$\begin{array}{c}\text { Franchise stores } \\
\quad \text { using LMS }\end{array}$ & 0 & 412 & 809 & 1404 \\
$\begin{array}{c}\text { Labor cost savings } \\
\text { (millions) }\end{array}$ & $\$ 3.51$ & $\$ 8.54$ & $\$ 11.89$ & $\$ 16.40$
\end{tabular}

Table 1: Growth in stores using the LMS and the corresponding yearly savings over FAST. the store. Before, with the FAST system, the manager was told how many hours of labor were allocated to the store. It was then his or her responsibility to decide how to most effectively deploy this labor. This resulted in variability in the level of service, hospitality, quality, and cleanliness among stores. Such variability is one of the most significant sources of customer dissatisfaction in the quick-service food industry. Eliminating variability increases customers' satisfaction, which leads to more frequent visits and hence to higher sales.

Another major benefit from the new LMS system is that it functions as a tool managers can use to schedule labor. A review of labor-scheduling practices by one of the authors revealed that, in a number of quick-food companies, managers tended to schedule too little labor to meet customer service goals during the peak hours, and too much during nonpeak hours of the day. This was attributed to both the difficulties in scheduling itself and the manager's perception that everybody tended to work faster during peak hours and the manager could always personally staff a position to resolve a bottleneck in production. Failing to deliver excellent service during peak periods can lower the sales curve for the entire day and vice versa, or as the well-known saying goes, "If you can't meet your sales, they will decrease until you can." The new LMS system has diminished this problem in the Taco Bell system.

\section{Enhancing Productivity}

Taco Bell also avoided costs by using the LMS to evaluate the impact on labor of a continuous stream of ideas for improving 


\section{HUETER, SWART}

key processes. Prior to the LMS, stakeholders debated the merits of suggestions for improvement based on qualitative factors. More often than not, the suggestions adopted were those supported by the highest ranking or most influential stakeholder. With the LMS, they could quantitatively evaluate the cost benefits of new ideas and make decisions on a rational basis for the first time.

By using the LMS to guide their efforts to reengineer work flow in the kitchen to eliminate non-value-added work, remove bottlenecks, and balance workloads, existing stores improved productivity by documenting savings of $\$ 13$ million per year in labor costs. Furthermore, the company has used the LMS to determine optimal drivethrough window and queue designs, to measure the benefits of alternative designs for point-of-sales communication devices, and to develop manual procedures for optimizing the man-machine performance of new technology investments.

\section{Enhancing the Return on Investment of New Buildings}

The LMS system was critical in supporting Taco Bell's decision to adopt the " $K$ minus" concept. Taco Bell removed the large traditional kitchens from its restaurants and transformed them into assembly-line areas for assembling products using prepared ingredients. The old kitchens had occupied 70 percent of the traditional Taco Bell restaurant, leaving only 30 percent for customer seating. Today, these proportions are reversed. Since then, the LMS has been an essential design instrument in Taco Bell's expansion to inline locations in malls and other locations that offer limited space and promise high- volume sales.

\section{Impact of New Equipment and Menu} Items

The company decided to provide free drink refills, which later led to self-service drink islands in restaurants, only after using the LMS extensively to determine the configuration, location, and staffing strategies that would minimize labor costs while maintaining customer-service standards. Before considering any new equipment, management uses the LMS to quantify its impact on labor and speed of service.

In its value strategy, Taco Bell introduced six core-menu items for the reduced price of 59 cents, and later expanded to a three-tier value menu of 59,79 , and 99 cents. This provided the impetus for the company's development of the LMS. In turn, the LMS was a crucial tool that allowed Taco Bell to achieve the operational efficiencies and cost savings that helped it to increase sales and earnings at an average of 20 percent or more each year between 1993 and 1996.

\section{Designing the Future}

Taco Bell is using the models of the LMS to develop labor-productivity pilot-test stores. Without it, the company could not assess the effectiveness and efficiencies of new technologies, including customeractivated touch screens (CATS), the fully automated taco maker, and the ergonomic workstation. While the models do not generate designs for the alternative technologies that could be incorporated in future Taco Bell restaurants, they can reliably predict which technologies should be incorporated based on labor cost and customer service. 


\section{TACO BELL}

\section{Conclusion}

This study took six years. The new LMS has now has been fully deployed as an integrated system in the entire Taco Bell system of company-owned stores. Almost four years have elapsed since its initial implementation, during which time virtually everybody has scrutinized and evaluated the performance of the system, from store managers to vice-presidents of operations and the CEO; however, a system like this is a living entity. Everybody in the corporation has a stake in it and has suggestions, criticism, praise, and questions. We must continually address these comments and make appropriate responses. In doing so, we continually improve the system and increase its contributions to the Taco Bell system. What is emerging in Taco Bell is the realization that there is another strategy for success, that of information and technology, which can take its place next to the traditional strategies of finance, marketing, and operations to help the firm succeed in this most competitive of industries.

\section{Acknowledgments}

Over the years, many individuals have contributed to the effort described in this paper. The LMS is a tribute to the people of Taco Bell, who once again have demonstrated that the organization is only as good as its people. We would like to recognize the contributions of the following former "Taco Bellers" who have left their mark on this study: Howard Frantz, now at In 'n Out; Mark Godward and Tom Wyczawski of Strategic Restaurant Engineering; and Jane Gannaway of Flagstar Corporation. Last, but not least, we wish to recognize the guidance and help pro- vided by our Edelman coach, Russ Labe of Merrill Lynch's private client group.

\section{References}

Everett, H. 1963, “Generalized Lagrangean multiplier method for solving problems of optimum allocation of resources," Operations Research, Vol. 11, No. 3, pp. 399-417.

Ford, L. R. and Fulkerson, D. R. 1962, Flows in Networks, Princeton University Press, Princeton, New Jersey.

Godward, M. and Swart, W. 1994, "An object oriented simulation model for determining labor requirements at Taco Bell," Proceedings of the 1994 Winter Simulation Conference, eds. Jeffrey D. Tew, S. Manivannan, Deborah A. Sadowski, and Andrew F. Seila.

Loucks, J. S. and Jacobs, F. R. 1991, “Tour scheduling and task assignment of a heterogeneous work force," Decision Sciences, Vol. 22, No. 4, pp. 719-738.

Makridakis, S. and Wheelwright, S. 1978, Interactive Forecasting, Holden-Day, Inc., San Francisco, California.

Mishra, D. 1982, “Computerized work measurement," in Handbook of Industrial Engineering, ed. G. Salvendy, John Wiley and Sons, New York.

Solomon, S. L. 1982, Simulation of Waiting Line Systems, Prentice Hall, Inc., Englewood Cliffs, New Jersey.

Swart, W. and Donno, L. 1981, "Simulation modeling improves operations, planning, and productivity of fast food restaurants," Interfaces, Vol. 11, No. 6, pp. 35-47.

Joaquin Pelaez, Senior Vice President of Technology and Quality for Taco Bell, said during the Edelman Competition presentation of the paper: "This is not just a labor management system. It is an incredibly powerful and adaptive decisionmaking tool to help us reliably predict the potential impact of new, strategic initiatives. ... To assess and avoid risk. ... Our ability to deliver superior shareholder value ... and attract investors is fundamentally strengthened." 